\title{
OPTIMAL VOLUME AND SLIP OF A THREE PHASE INDUCTION MOTOR USING DIFFERENTIAL EVOLUTION
}

\author{
J. A. Malagoli' ${ }^{1}$ J. H. I. Ferreira ${ }^{1}$, J. R. Camachoํ, M. V. Ferreira da Luz ${ }^{2}$ \\ ${ }^{1}$ Faculty of Electrical Engineering, Federal University of Uberlândia \\ Av.: João Naves de Ávila, no 2121, Bairro: Santa Mônica, CEP: 38.408-100, Uberlândia-MG, Brazil \\ ${ }^{2}$ Departament of Electrical Engineering, Federal University of Santa Catarina \\ Campus Universitário Reitor João David Ferreira Lima, Trindade, CEP: 88.040-970, Florianópolis-SC, Brazil \\ E-mail: juliana.malagoni@gmail.com, jacson@iftm.edu.br, jrcamacho@ufu.br, mauricio.luz@ufsc.br
}

\begin{abstract}
The multiobjective engineering project is inherently conflicting. It provides an improvement in one of the objectives, but a decline in the other. The three phase induction motor with a wound rotor is widely used in the industry, because it's simple, resistant and cheap compared with other types of engines. Regarding the context explained above, it is an interesting research theme, which is directly related to the fabrication costs of the engines. The object of this article, is the formulation and resolution of the three phase induction motor considering: (i) volume minimization and (ii) motor slip minimization. For this purpose the MODE (Multiobjective Optimization Differential Evolution) algorithm, was used, and the results are confronted with those obtained with the NSGA II (Non-dominate Sorting Genetic Algorithm).
\end{abstract}

\section{Key words}

Differential Evolution, Induction Motor, Multiobjective Optimization

\section{Introduction}

The three phase motor induction (TIM) is widely used for industrial purposes, due to constructive aspects, virtually constant velocity, cost, and because it is connected to an alternating current (AC), among other aspects [1].

The TIM differs from other types of engines, since there is no external supply to the rotor [2]. The voltages and currents are produced by induction, which can be mono phase or three phase.

Today market competition is increasingly fierce, any cost reduction represents a significant portion in the increase of competitiveness, obliging the companies to invest progressively in tools that guarantee productivity and quality towards their products [2]-[3].

When analyzing electric engines, electric energy and maintenance represent the biggest portion of their operational costs, during their life span. And $55 \%$ of Brazil's industrial consumption, according to ELETROBRAS, is due to electric motors. Owing to its broad usage, considering inappropriate specifications and application, a flaw can entail big production losses, affect security or even the environment [1]. When this happens, it is vital that actions must be taken, quickly and assertively, to reinstate the process, minimizing losses [4].

These scenarios bring forth big potential in optimizing costs, regarding electric engines. Reaffirming the importance of using good practices to select and maintain these equipment [3].

When dealing with a project in engineering systems, the main goal is to manufacture a machine to accomplish a specific task with efficiency and economy[4]. The problem in projecting and building electric machines is to do it, as economically as possible, and that encloses a predetermined set of specifications [4].

Traditionally, the project of induction motors has been contemplated to achieve improvements in performance or reduction costs. It is notorious that, any significant improvement in operational efficiency of the induction motor implies in energy conservation [5]. Energy efficiency of a motor can be optimized reducing the importance of active material used, which can be accomplished by bringing down the diameter and length of the machine, or in other words, through minimization of volume and slip of the three phase induction motor [4].

The next sections of this article are organized, as following: in section 2 will be addressed the construction of a three-phase induction motor with a wound rotor. In section 3 the algorithm of differential evolution will be described. Section 4 will pose the methodology and strategies used to optimize the three phase induction motor. Section 5 presents the discussion and obtained results. And in section 6 are the final comments.

\section{Three phase Motor with a Wound Rotor}

The TIM is basically composed by two parts: the rotor and stator [1]-[3]. 
The constitution of the rotor is an axis (spindle, pivot, hub, kingpin) that conveys mechanical energy. It has a "set" of magnetic plates (core), which goal is to improve the magnetic permeability of the surroundings, with little loss to hysteresis and Foucault [2]. The winding can be wound or "squirrel cage". The wound rotor is a three phase winding, closed internally as a star, with three terminals connected externally in sequence with a three phase resistor or in a short circuit.

The stator is formed by a frame or a carcass, that is the structure of the ensemble, and is normally built with cast iron [1]. There is a core, that is a "set" of magnetic plates, which has the same function as the core of the rotor: concentrating the induction lines, created by the conductors, connected to an alternating current. In the slots of the core of the stator, there is a three phase winding, composed of three sets of copper or aluminum coils, that are geometrically displaced by $120^{\circ}$ [2]. These coils interact, generating a rotating magnetic field, that is only possible due to the stator geometry (the coils are displaced), and fed by three phase alternating currents, which phases are displaced by $120^{\circ}$ electric [2]. The main equations of the three phase induction motor are presented in sequence.

The Output Equation: is the mathematical expression that provides the relation between the physical parameters and electric parameters of the electric machine. The output equation refers to the output of the induction motor, with the main dimensions of the stator, and represents the tool used to initiate the draft. The output of the three phase induction motor is [1]-[3]:

$$
Q=C D^{2} L N \quad(k W)
$$

Which:

$N$ is the speed (r.p.m);

$L$ is the length of the machine $(m)$;

$D$ is the internal diameter of the stator $(m)$;

$C$ is the output coefficient, represented by:

$$
C=18.3 \cdot 10^{-5} k_{w s} B_{a v} \text { ac } \eta \operatorname{Cos} \varphi
$$

Separation of $D$ and $L$ : the output equation provides the relation between the product $D^{2} L$ and the output of the machine. To separate $D$ and $L$, for this product a ratio has to be assumed or established [1]-[3]. The variables of the project are defined in sequence, based upon the assumption that an adequate ratio between the gross length and pole pitch, can be assumed [2]. To obtain:

- Minimum cost is between 1.5-2.0;

- Good efficiency is between $1.4-1.6$;

- A good project is between $1.0-1.1$;

- A good factor is between $1.0-1.3$.

As the factor has an important role in the performance of the three phase induction motor, it is advisable to design an induction motor, with the best factor unless it is specified otherwise in the project.

Thus to obtain a better factor, the relation in sequence will be assumed to separate $D$ and $L$ [1]-[5].

$$
D=0.135 P \sqrt{L} \quad(m)
$$

Which:

$P$ is the number of poles.

And the pole pitch is,

$$
\tau_{p}=\frac{\pi D}{P} \quad(m)
$$

Using the previous relation between $D$ and $L$ they can be separated, due the product $D^{2} L$.

Total loss with copper: the mean turn length, can be calculated through the empirical equation [1]-[4].

$$
l_{m t}=2 L+2,3 \tau_{p}+0.08
$$

The resistance of the winding of the rotor is obtained:

$$
R_{r}=\frac{0.021 l_{m t} T_{r}}{A_{r}}
$$

Which:

$T_{r}$ is the number of conductors by slot of the rotor;

$A_{r}$ is the section area of the conductors of the rotor $\left(\mathrm{mm}^{2}\right)$.

Total loss in copper is,

$$
P_{t c u}=3 I_{r}^{2} R_{r}
$$

The slip for a three phase induction motor with wound rotor is [1]:

$$
s=\frac{P_{t c u}}{Q+P_{t c u}} 100
$$

The volume of the machine is represented by [1]:

$$
V o l=D^{2} L \quad\left(m^{3}\right)
$$

\section{Multiobjective Optimization Differential Evolution}

Can be found in literature, innumerous attempts to extend Differential Evolution (DE) to solve problems, with different purposes. Due the success of the application of Differential Evolution (DE), within the range of science and engineering, it is applied to this project.

Specifically, in this study case is used the MODE (Multiobjective Optimization Differential Evolution) algorithm proposed by Lobato [6]. This approach is based on the DE algorithm and has the following structure: the initial population is randomly generated. All the dominated solutions are removed from the population through an operator classified as nondominated. So the population is classified in nondominated curves (sets of vectors that aren't dominated between each other) [6]. This procedure is repeated until each vector is part of a curve. Three parents are selected 
randomly in the population. A child is engendered from the three parents (this process continues until the children are generated). The MODE algorithm is demonstrated through the flowchart:

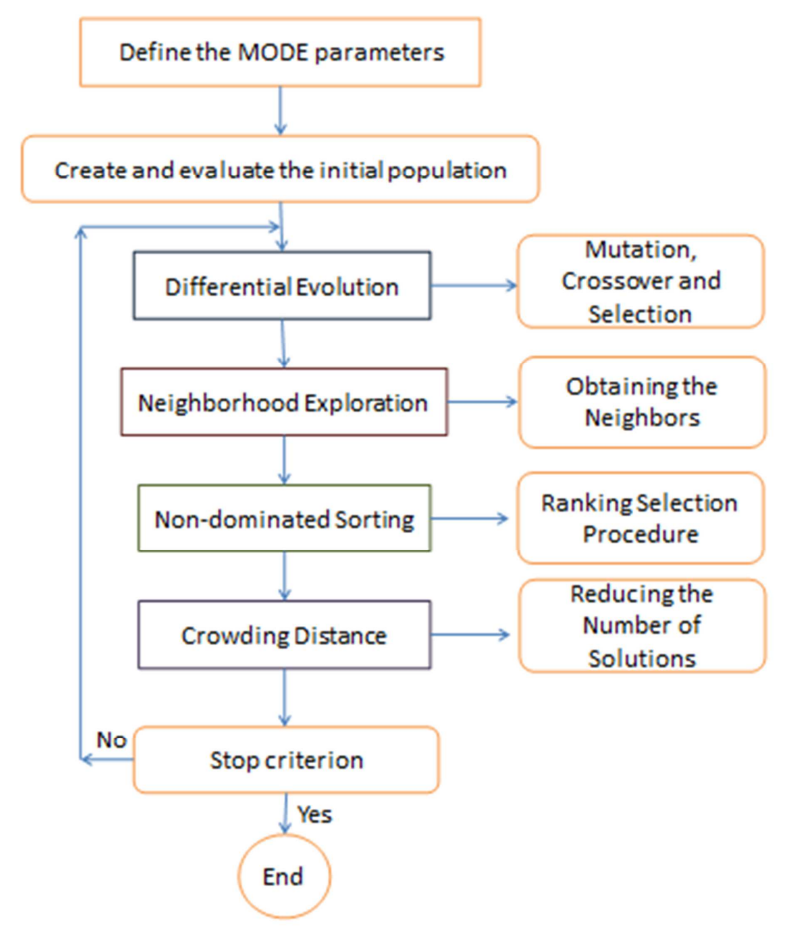

Fig. 1. MODE algorithm flowchart.

The differential evolution proposed by Price and Storn [7], is an improved version of the genetic algorithm of Goldberg [8] that complies the following advantages: optimization, simple structure, ease, speed and robust results [9]. The fundamental idea of DE is a structure to produce evaluating parameter vectors. Essentially, DE adds the weighted difference between two vectors of the population, to a third vector. The main control parameters of DE are: size of the population $(N P)$, a cross probability $(C R)$, and the weight applied to the random differential $(F)$.

Price and Storn provided some simple rules to choose the main DE parameters, for any application [7]. Normally, $(N P)$ must be 5 to 10 times the dimension (number of parameters of a vector) of the problem. As for the $(F)$, is found between 0.4 and 2.0. Initially $(F=0.5)$ can be accepted, and $(F)$ and/or $(N P)$ is enhanced if the population converges prematurely.

According to literature, countless applications are found for the DE algorithm, in distinct areas of science, to mention some: engineering systems project [6], engineering systems project with a multiobjective focus [10], considerations about failure tolerant slots in synchronous motors [11], a study in evolutionary algorithms of multiobjective optimization for the induction motor project [12], a study in a switched reluctance motor using swarm particles optimization [13], project and optimization of a three phase induction motor using a genetic algorithm [14], besides other applications [9].

\section{Methodology}

As previously mentioned, this project consists in slip minimization and minimization of the volume regarding the material used to produce the motor, applying the differential evolutionary algorithm. To better understand the methodology used in this article, some points must be highlighted:

- The goal is to minimize the volume function ( $\mathrm{Vol}$ ) and the slip function $(s)$;

- The variables of the project are: $(a c)$ specific electric charge $(A / m),\left(B_{a v}\right)$ mean value of the electric charge $(T),\left(J_{s}\right)$ current density on the winding of the stator $\left(A / \mathrm{mm}^{2}\right), \quad\left(J_{r}\right)$ current density on the winding of the rotor $\left(A / \mathrm{mm}^{2}\right),\left(L / \tau_{p}\right)$ ratio of the length of the pole pitch, $\left(h_{s}\right)$ height of the stator slot $(\mathrm{mm}),\left(h_{r}\right)$ height of the rotor slot $(\mathrm{mm}),\left(b_{s}\right)$ the width of the stator slot $(m m),\left(b_{r}\right)$ the width of the rotor slot $(m m),\left(b_{t s 1}\right)$ width of the tooth of the stator $(m m),\left(b_{t r 1}\right)$ width of the tooth of the rotor $(\mathrm{mm})$;

- The parameters used with the MODE algorithm: 50 individuals, 200 generations, the disturbance rate and the crossover probability equal to 0.9 and strategy $\mathrm{DE} / \mathrm{rand} / 1 / \mathrm{bin}$ to generate potential candidates, the reduction rate and the number of pseudo-curves is 0.9 and 10 , respectively;

- Stop or halt criteria: an amount of generations are defined to discontinue the process;

- Number of actions: 10 tests executed to obtain a better result;

The attained results with the MODE algorithm are compared to the results obtained with the NSGA II algorithm.

To resort, to the proposed methodology, was used a three phase induction motor of $18.5(\mathrm{~kW}), 220(\mathrm{~V}), 60(\mathrm{~Hz}), 4$ (poles) e 1800 (r.p.m).

Table 1, shows the results of the project and the main functions, the equations were based upon the project of the three-phase induction motor with a wound rotor.

Table I. The parameters of the three phase induction motor.

\begin{tabular}{cc}
\hline Parameters & $\begin{array}{c}\text { Analytical } \\
\text { Calculation }\end{array}$ \\
\hline$a c$ & $10000,00(\mathrm{~A} / \mathrm{m})$ \\
\hline$B_{a v}$ & $0.30(\mathrm{~T})$ \\
\hline$J_{s}$ & $3.50\left(\mathrm{~A} / \mathrm{mm}^{2}\right)$ \\
\hline$J_{r}$ & $3.50\left(\mathrm{~A} / \mathrm{mm}^{2}\right)$ \\
\hline$L / \tau_{p}$ & 1.50 \\
\hline$h_{s}$ & $25.39(\mathrm{~mm})$ \\
\hline$h_{r}$ & $16.31(\mathrm{~mm})$ \\
\hline$b_{s}$ & $8.75(\mathrm{~mm})$ \\
\hline$b_{r}$ & $7.87(\mathrm{~mm})$ \\
\hline$b_{t s 1}$ & $32.47(\mathrm{~mm})$ \\
\hline$b_{t r 1}$ & $41.94(\mathrm{~mm})$ \\
\hline$V o l$ & $0.0311\left(\mathrm{~m}^{3}\right)$ \\
\hline$s$ & $5.00(\%)$ \\
\hline
\end{tabular}


The MODE algorithm is used, and to confront the results, the NSGA II is also applied (optimization techniques used to solve different problems). The intention is to adapt them to the proposed problem in this study case, and subsequently solve it to attend our goals of minimizing the volume and the slip of the motor.

\section{Results and Discussion}

The equations (8) and (9) are regarded, as main functions of the problem studied in this article. The goal is to minimize the volume and slip functions of the motor (on the Pareto curves points A, B, C, D and E are analyzed) and to evaluate the proposed methodology.

The main function $(F O)$, the inferior, superior limits and restrictions are presented, in sequence:

$F O=\left\{\begin{array}{l}\min f_{1}=D^{2} L+\text { restrictions } \\ \min f_{2}=\frac{P_{t c u}}{Q+P_{t c u}} 100+\text { restrictions }\end{array}\right.$

Variables $=\left\{\begin{array}{l}10000 \leq x(1) \leq 30000 \\ 0.30 \leq x(2) \leq 0.60 \\ 3.0 \leq x(3) \leq 6.0 \\ 3.0 \leq x(4) \leq 6.0 \\ 0.90 \leq x(5) \leq 2.0 \\ 15 \leq x(6) \leq 45 \\ 10 \leq x(7) \leq 25 \\ 15 \leq x(8) \leq 45 \\ 15 \leq x(9) \leq 45 \\ 5 \leq x(10) \leq 15 \\ 5 \leq x(11) \leq 12.5\end{array}\right.$

restrictions $=\left\{\begin{array}{l}g(1)=3 x(10)-x(6) \\ g(2)=2 x(11)-x(7)\end{array}\right.$

Tables 2 and 3 show the outcomes of the Pareto curve (Fig. 2) attained by the MODE algorithm.

Table II. Outcomes drawn from the MODE algorithm, considering the variables $x(1), x(2), x(3), x(4), x(5), x(6)$ and $f(2)$ for the main function $(F O)$.

\begin{tabular}{|c|c|c|c|c|c|c|c|}
\hline Points & $a c$ & $B_{a v}$ & $J_{s}$ & $J_{r}$ & $L / \tau_{p}$ & $h_{s}$ & $S$ \\
\hline A & 10040.75 & 0.59 & 5.62 & 3.00 & 1.90 & 26.83 & 2.72 \\
\hline $\mathrm{B}$ & 23353.47 & 0.59 & 5.53 & 3.00 & 1.96 & 22.97 & 3.73 \\
\hline $\mathrm{C}$ & 10297.68 & 0.59 & 4.91 & 3.00 & 1.97 & 43.31 & 2.72 \\
\hline $\mathrm{D}$ & 11393.84 & 0.59 & 4.73 & 3.00 & 1.80 & 44.30 & 2.85 \\
\hline$E$ & 25588.29 & 0.59 & 3.37 & 3.00 & 1.92 & 44.30 & 3.84 \\
\hline
\end{tabular}

Table III. Outcomes drawn from the MODE algorithm, considering the variables $x(7), x(8), x(9), x(10), x(11)$ and $f(1)$ for the main function $(F O)$.

\begin{tabular}{ccccccc}
\hline Points & $h_{r}$ & $b_{s}$ & $b_{r}$ & $b_{t s 1}$ & $b_{t r 1}$ & $V o l$ \\
\hline A & 18.70 & 7.48 & 9.09 & 29.93 & 42.87 & 0.0156 \\
\hline B & 21.54 & 7.08 & 9.04 & 22.80 & 30.42 & $\mathbf{0 . 0 0 6 7}$ \\
\hline C & 16.84 & 11.95 & 5.55 & 31.41 & 33.12 & 0.0152 \\
\hline D & 16.20 & 10.16 & 5.35 & 38.39 & 32.91 & $\mathbf{0 . 0 1 3 7}$ \\
\hline E & 23.22 & 8.35 & 9.62 & 22.88 & 27.82 & $\mathbf{0 . 0 0 6 1}$ \\
\hline
\end{tabular}

Were highlighted, in tables II and III the best values for functions $f(1)$ and $f(2)$ considering $(F O)$ for MODE algorithm.

Figure 2 shows the Pareto curve attained through the MODE algorithm considering $(F O)$ (minimizing the volume and slip of the three phase induction motor).

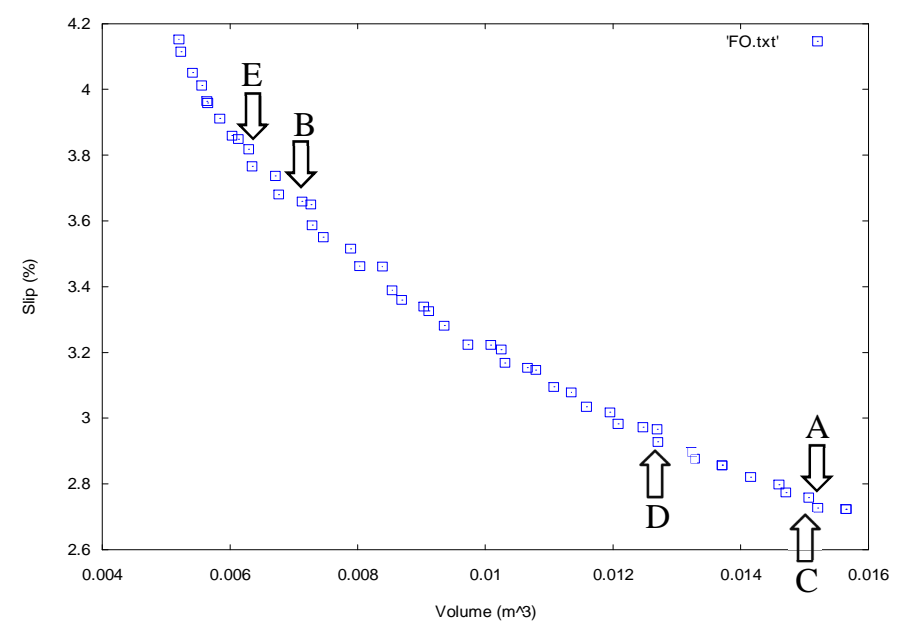

Fig. 2. Pareto curve outcome drawn from MODE considering $\mathrm{FO}$.

The tables IV and V show the results from the Pareto curve (see Fig. 3) attained from the NSGA II algorithm considering $(F O)$.

Table IV. Results obtained through the NSGA II algorithm and variables $x(1), x(2), x(3), x(4), x(5), x(6)$ and $f(2)$ for the $(F O)$ function.

\begin{tabular}{cccccccc}
\hline Points & $a c$ & $B_{a v}$ & $J_{s}$ & $J_{r}$ & $L / \tau_{p}$ & $h_{s}$ & $s$ \\
\hline A & 10011.30 & 0.60 & 5.35 & 3.00 & 1.85 & 35.81 & $\mathbf{2 . 7 0}$ \\
\hline B & 16949.50 & 0.60 & 5.11 & 3.00 & 1.99 & 34.55 & $\mathbf{3 . 2 7}$ \\
\hline C & 10885.40 & 0.60 & 4.55 & 3.00 & 1.98 & 36.72 & $\mathbf{2 . 7 7}$ \\
\hline D & 27717.90 & 0.60 & 5.42 & 3.00 & 1.99 & 40.15 & 3.92 \\
\hline E & 18294.00 & 0.60 & 4.91 & 3.00 & 1.97 & 40.09 & 3.36 \\
\hline
\end{tabular}

Table V. Results obtained through the NSGA II algorithm and variables $x(7), x(8), x(9), x(10), x(11)$ and $f(1)$ for the $(F O)$ function.

\begin{tabular}{ccccccc}
\hline Points & $h_{r}$ & $b_{s}$ & $b_{r}$ & $b_{t s 1}$ & $b_{t r 1}$ & Vol \\
\hline A & 17.79 & 8.09 & 7.68 & 23.29 & 31.87 & 0.0155 \\
\hline B & 24.37 & 7.84 & 7.84 & 33.14 & 34.53 & $\mathbf{0 . 0 0 9 2}$ \\
\hline C & 17.13 & 8.34 & 6.65 & 23.18 & 31.82 & 0.0143 \\
\hline D & 18.66 & 7.36 & 5.50 & 18.69 & 45.00 & $\mathbf{0 . 0 0 5 6}$ \\
\hline E & 19.24 & 8.05 & 6.03 & 22.47 & 28.74 & $\mathbf{0 . 0 0 8 5}$ \\
\hline
\end{tabular}

Figure 3 shows the Pareto curve attained through the NSGA II algorithm for $(F O)$ (minimizing the volume and slip of a three phase induction motor with a wound rotor). 


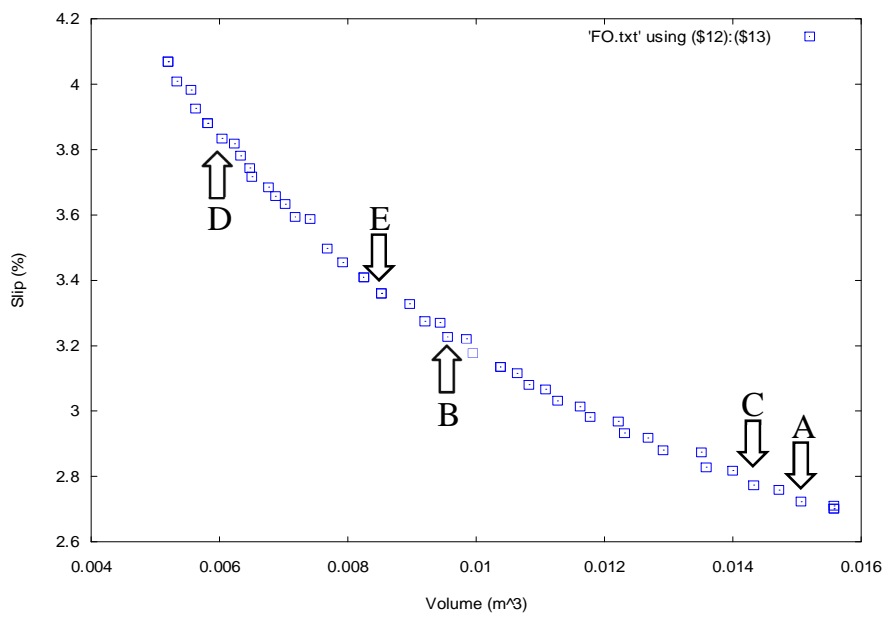

Fig. 3. Pareto curve obtained through the NSGA II for $(F O)$.

Observing the Pareto curves, the outcomes were very close. The best results from table I were compared to table III, and there was a volume reduction of 55,94 (\%). From table I to table II there was a slip reduction of 43,00 (\%). From point $\mathrm{D}$ of table I compared to the same point in table $\mathrm{V}$ there was a 54,01 (\%) volume reduction. And from table I to table IV a slip reduction of 44,60 (\%), considering point $\mathrm{C}$ in both tables. Analyzing the outcomes, the methodology applied was able to minimize and maximize the functions for the observed cases.

\section{Conclusion}

The MODE algorithm was used to optimize the three phase induction motor with a wound rotor. Two main functions were considered: slip and volume of the motor. The results attained, showed that the methodology used is an interesting approach to the treatment of the formulated problem.

For future studies, it is suggested to apply the methodology in industries, and optimization of projects in electric machines to minimize costs and maximize efficiency.

\section{References}

[1] R. K. Agarwal. "Principles of Electrical Machine Design". Katson Books, 2000.

[2] V. N. Mittle, A. Mittal. "Design of Electrical Machines". Standard Publishers Distributors, Delhi, 2009.

[3] K. G. Upadhyay. "Design of Electrical Machines". New Age International Publishers. New Delhi, India, 2008.

[4] J. A. Malagoli, F. S. Lobato, J. R. Camacho, M. V. Ferreira da Luz. "Projeto de Estator de Máquina de Indução Trifásica Usando o Algoritmo de Evolução Diferencial". Simpósio de Mecânica Computacional e Encontro Mineiro de Modelagem Computacional, Vol. 1, (pp. 1-13), Juiz de Fora-MG, Brasil, 2014.

[5] J. A. Malagoli, J. R. Camacho, M. V. Ferreira da Luz. "Projeto de Rotor de Máquina de Indução Trifásica Usando o Algoritmo de Evolução Diferencial". Simpósio Brasileiro de Micro-ondas e Optoeletrônica e Congresso Brasileiro de Eletromagnetismo, Curitiba-PR, Brasil, 2014.

[6] F. S. Lobato. "Multiobjective Optimization to Engineering System Design". Doctoral Thesis, School of Mechanical Engineeing, Universidade Federal de Uberlândia, Brasil, 2008.

[7] K. Price, R. Storn. "Differential Evolution - A Simple Evolution Strategy for Fast Optimization", Dr. Dobb's Journal, v. 22, pp. 18-24, April, 1997.

[8] D. E. Goldberg. "Genetic Algorithms in Search, Optimization, and Machine Learning", MA: Addison-Wesley, 1989.

[9] R. Storn, K. Price, J. A. Lampinen. "Differential Evolution - A Practical Approach to Global Optimization”. Springer: Natural Computing Series, 2005.

[10] F. S. Lobato, V. Steffen Jr. "Engineering System Design with Multiobjective Differential Evolution", in Proceedings of the 19th International Congress of Mechanical Engineering, 2007.

[11] N. Bianchi, M. Dai Pré, G. Grezzani, S. Bolognani. "Design considerations on fractional-Slot FaultTolerant Synchronous Motors", IEEE, 2005.

[12] S. Yasodha, K. Ramesh, P. Ponmurugan. "Evolutionary Multiobjetive Optimization Algorithms For Induction Motor Design - A Study", International Journal of Emerging Technology and Advanced Engineering, Vol. 2, Issue 11, November, 2012.

[13] W. Phuangmalai, M. Konghirun, N. Chayopitak. "A Design Study of 4/2 Switched Reluctance Motor Using Particle Swarm Optimization", ECTI Transactions on Electrical Eng., Electronics, and Communications, Vol. 11, no 1, February, 2013.

[14] A. Raghuram, V. Shashikala. "Design and Optimization of Three Phase Induction Motor Using Genetic Algorithm", International Journal of Advances in Computer Science and Technology, Vol. 2, n 6, June, 2013. 